DOI 10.37882/2223-2982.2021.03-2.26

\title{
ЭКЗИСТЕНЦИАЛЬНЫЕ ОСНОВЫ КОНЦЕПТОСФЕРЫ СЧАСТЬЯ: АНАЛИЗ ИДЕЙ ПРОШЛОГО В СВЕТЕ КОВИДНОГО НАСТОЯЩЕГО
}

\section{EXISTENTIAL BASIS OF THE CONCEPTOSPHERE OF HAPPINESS: ANALYSIS OF THE IDEAS OF THE PAST IN THE LIGHT OF THE COVID PRESENT}

\section{T. Makarova}

Summary: The article highlights the linguistic means of expressing the concept of happiness in foreign linguistic cultures. The material is heavily based on the novel «The Plague» by A. Camus and the plays of the American playwright $\mathrm{E}$. Albee «Who is afraid of Virginia Woolf? " and «Three Tall Women», belonging to the culture of the absurd. The specific features of the linguistic projection of the concept of happiness are analyzed from the standpoint of existentialism. Linguistic means of objectification of the concept allow us to identify its humanistic core. Translations of authentic texts were performed by the author.

Keywords: pandemic, model of happiness, existential crisis, concept, dramaturgy of the absurd.

\author{
Макарова Татьяна Генриховна \\ К.и.н., дочент, Российский экономический университет \\ имени Г.В. Плеханова, г. Москва \\ fortunatat@mail.ru
}

Аннотация: Статья посвящена языковым средствам выражения концепта счастья в зарубежных лингвокультурах. Материалом для исследования послужили роман А. Камю «Чума» и пьесы американского драматурга Э. Олби «Кто боится Вирджинии Вульф?» и «Три высокие женщины», принадлежащие к культуре абсурда. С позиций экзистенциальной парадигмы рассматривается специфика языковой проекции концепта «счастье». Лингвистические средства объективации концепта позволяют судить 0 его гуманистической направленности. Переводы аутентичных фрагментов выполнены автором.

Ключевые слова: пандемия, модель счастья, экзистенциальный кризис, концепт, драматургия абсурда.

\begin{abstract}
$\mathrm{C}$ тремительное распространение пандемии COVID-19, охватившей в 2020 г. большое число стран и народов, высветило неоспоримую ценность человеческой жизни, сохраняющую свою значимость в трудных условиях атаки на глубинные основы ее существования. При этом характерным трендом исследований «ковидного периода» стало не примитивное декларирование ценности человеческой жизни как таковой, а рассмотрение ее в широком социальном контексте жизнедеятельности и взаимодействия людей, как ответа на вынужденные барьеры и самоизоляцию. В трудные периоды кризисов неизменно возрастает интерес мирового сообщества к эмоционально-значимой теме счастья. Вопрос о природе счастья оставил глубокий след в мировой культуре, нашел свое отражение в философских трудах, в художественной литературе, в устном народном творчестве. Справедливо можно говорить о концептуализации философско-нравственной категории счастья и ее интеграции в лингвокультуры различных народов. В XXІом веке расширяются национальные границы концепта, о чем свидетельствует принятие резолюции Генеральной Ассамблеи ООН A/ $\mathrm{RES} / 66 / 281$ (2012 г.) об объявлении Международного дня счастья. Ежегодно в этот день весеннего равноденствия 20 марта публикуется World Happiness Report - исследование степени удовлетворенности жизнью населения в различных странах мира [1]. В стремлении обеспечить себе эффективное прогнозирование социального са-
\end{abstract}

мочувствия общества, Правительства и власть имущие предпринимают усилия по изучению источников счастья, добавляя в «алгебраическую» формулу счастья все новые множители.

В Российских СМИ прослеживаются попытки выделить некий «индекс счастья» в качестве показателя социального благополучия, отражающего базовые представления об общественной детерминированности человеческой жизни. Публикуются индексы счастья российских городов, изучается опыт национальных моделей счастья: «шведский образ - минимализм и баланс во всем», «финский образ - талант расслабления», «российский вариант - борьба за справедливость и успешная коммуникация» [2]. Социологическая наука стремится измерить уровень счастья в статике и динамике, расширить таргетную аудиторию охвата за счет основных социально-демографических групп. На фоне пандемии коммерческие структуры вводят вакансию «директора по счастью», который призван разработать некую дизайн-модель улучшения социального самочувствия сотрудников компании в условиях хаоса и тотальной неопределенности [2]. Представляется, что в основе этой проектной деятельности лежит признание счастья и благополучия как общечеловеческих ценностей и целенаправленных устремлений людей всего мира, равно как и учет их важного значения для построения эффективной государственной политики в рамках взаимодей- 
ствия и гражданского согласия.

Вместе с тем, жестко-детерминированная модель «общественно-обусловленного счастья», базирующаяся на синергии стремления человека к материальному благополучию и ответной социальной политике государства, в наши дни переживает кризис доверия и с трудом инкорпорируется в область личностного сознания индивида, помещенного в трудные условия безработицы, духовного упадка и утраты смысла жизни на фоне пандемии COVID-19. Все большее число людей заявляют об экзистенциальном кризисе, т.е. совокупном кризисе бытия. Тем не менее, государство продолжает формировать футуристическую оптимистическую модель и старается находить подтверждения социального оптимизма граждан. В этом контексте уместно вспомнить идеи великого культуролога и гуманиста академика Лихачева Д.С., который предрекал низкую эффективность любых построений, основанных на однозначности и терминологичности и лишенных богатого исторического эмоционального и национального опыта [3]. Поэтому представляется весьма актуальным в качестве предмета исследования рассмотреть концептуализацию категории счастья в зарубежных лингвокультурах, возникшую в рамках антропоцентрических исканий философии экзистенциализма прошлого века. В силу ряда причин (подавление инакомыслия и свободы творчества) она не получила развития в России. Согласно экзистенциальной парадигме, человек способен самостоятельно определять, для чего ему жить и к чему стремиться, осуществлять свой свободный выбор без оглядки на «социальный заказ», принимать свои собственные решения безо всяких предписывающих оснований.

В поисках психологических опор преодоления вызванного пандемией кризиса, мировое сообщество обратилось к идеям французского философа Альбера Камю. Всемирный экономический форум включил роман «Чума» (1947 г.) в список пяти книг, которые могут помочь людям научиться выживать в условиях COVID-19. Большинство исследователей акцентировало внимание на главном персонаже романа Докторе Бернаре Риэ, отважно вступившем в борьбу с бубонной чумой в Оране (Алжир), усматривая в этом несгибаемом одиночке индивидуальную экзистенциальную модель поведения, противостоящую общему абсурду окружающей жизни. И если, по признанию автора, окончательная победа над абсурдом бытия невозможна, а самоотверженного Доктора Риэ ждет «бесконечное поражение», то, тем не менее, в его каждодневном выполнении рутинной работы, в этой «обнаженности перед абсурдом» А. Камю усматривал противодействие общему расширению абсурдности в мире [4]. Умение сохранять спокойствие, мужество и стойкость граждан обеспечивают им победу над эпидемией. В конце романа Риэ слышит доносящийся с улицы счастливый смех горожан. Выполнение про- фессионального долга и достоинство помогают выстоять отдельной личности, питают веру в успешное окончание ниспосланных свыше испытаний. В комментарии на тему романа «Чума», опубликованном Университетом Штата Колорадо, США, в августе 2020 г., отмечалось, История Альбера Камю напоминает нам об огромном уважении и восхищении человеческим духом, когда нас постигает такая чума, как COVID-19 [5].

Но не только эпидемии разрушали жизненный путь человека. Любые военные конфликты приносят неимоверные страдания людям, вынужденным бороться за выживание в условиях голода, распада социальных связей и экономической рецессии. Коллективная рефлексия общества, замешанная на недоверии к государственным институтам, порой давала причудливые иррациональные ответы на вызовы трагического прошлого. Релевантным примером может послужить литература и драматургия абсурда, возникшие в европейском обществе как прямая реакция на духовный крах и отчаяние в период после Второй мировой войны. Поступательный ход истории, ее цельность и линейность были нарушены. Великие смыслы исторического прогресса были развенчаны трагическими событиями Второй мировой войны, а последовавший мир представлялся многим как бессмысленное, лишённое логики нагромождение фактов, поступков, слов и судеб [6]. Театр абсурда, как часть абсурдистской культуры, возник на разрушенных обломках психологического театра, противопоставив психологической мотивированности и обоснованности полное нарушение причинно-следственных связей в поведении и поступках персонажей. Целеполагание стало синонимом тупика. Попытки вернуть дегуманизированный мир к гармонии были объявлены несостоятельными; время и место, как факторы событийности, растворились в неопределенности. Тем не менее, театр абсурда не стал тотальным декадансом и рупором небытия. Помещенные в мир абсурда, его действующие лица готовы демонстрировать индивидуальную стойкость и свое экзистенциальное противостояние абсурду [7]. Они часто задумываются о счастье, но их ощущения счастья характеризуется немотивированной изменчивостью, внутренней противоречивостью и парадоксальностью.

Одним из тех, кто воплотил принципы абсурдизма в американской лингвокультуре, был писатель и драматург Эдвард Олби (Edward Albee, 1928-2016), лауреат премии Центра Кеннеди за плодотворно прожитую жизнь, обладатель высшей награды газеты «Чикаго Трибьюн» (2013 г.) за вклад в литературную деятельность в номинации «глубокое проникновение в психологию взаимоотношений между людьми». На протяжении своей жизни Эдвард Олби неоднократно удостаивался высоких литературных призов, в частности за пьесу «Шаткое равновесие» (A Delicate Balance, 1966), (в переводе на русский можно встретить вариант перевода назва- 
ния «Неустойчивое равновесие»), он получил ежегодную премию «Тони» и первую Пулитцеровскую премию (1967); в 1975 ему была вручена вторая Пулитцеровская премия за пьесу «Морской пейзаж» (Seascape, 1975).

Творчество Э. Олби хорошо известно российскому читателю, в разные годы его пьесы в переводе с английского шли на ведущих театральных площадках страны. Его драматургической манере свойственны нестандартные жизненные ситуации, в которые он помещает своих героев. Однако, преодолевая всевозможные препятствия и душевную боль, они не перестают размышлять о своем предназначении и базовых категориях человеческого бытия, к которым, несомненно, относится понятие «счастье». Языковая картина мира и концепт - суть основные категории, сформированные в русле антропоцентрической парадигмы современной лингвистики, согласно которой в центре исследования стоит человек, важнейшей характеристикой которого является языковая способность к выражению мысли и восприятию речи. Зарождаясь в индивидуальном сознании автора, этот концепт через речевую культуру конкретных героев, наделяемых автором определенным объемом речевых средств, обретает самостоятельную жизнь, конституируется благодаря длительности жизни литературного произведения в исторически передаваемую систему представлений и установок, и со временем обретает собственное независимое звучание, образуя пласт совокупной концептосферы этого языка, который в свою очередь органично вплетается в общую духовную культуру общества. Исследователь национальных концептов и создатель словаря русской культуры Степанов Ю.С. указывал на нелинейность в их формировании и выражении, поскольку «концепты не только мыслятся, они - переживаются. Они - предмет эмоций, симпатий и антипатий, а иногда и столкновений» $[8$, с. 46$]$.

Пьеса «Кто боится Вирджинии Вулф?» (“Who's Afraid of Virginia Woolfe?", 1962), относящаяся к числу ранних работ автора, служит достойным подтверждением этого постулата. В свое время она удостаивалась престижной премии «Тони» и стала всемирно известной после экранизации 1966 г., в которой роль Марты сыграла непревзойденная Элизабет Тейлор. В этой пьесе уже явственно проступает специфика авторской концептосферы счастья, опровергающая традиционный набор прописных жизненных истин. Матрица счастья Э. Олби противостоит благополучию и прочности семейных уз. Она вырастает из крушения надежд и нереализованности человеком своего предназначения. Марта, дочь Ректора Университета, и ее муж Джордж, сотрудник этого Университета (обоим за сорок), чувствуют глубокую неудовлетворенность жизнью, неосуществимость своих желаний, и в силу этого постоянно демонстрируют взаимное раздражение. Она не устает повторять ему, что он - размазня, ноль, ничтожество, пустое место, пугало болотное, неудачник, не сделавший академическую карьеру, не способный стать деканом исторического факультета, не то, что Ректором, несмотря на солидную протекцию со стороны семьи. Он не уступает жене, отмечая ее скверные наклонности, алкоголизм и талант склочности, что вынуждает его жить как во сне, постоянно подавляя свои эмоции. Она же вновь и вновь обвиняет мужа в беспомощности, в невозможности найти с ним общий язык, что приводит к тому, что в своем конструктивном стремлении правильно организовать и направить его по жизни в ней генерируется некая вынужденная разрушительная сила [9]. И тем не менее, именно антагонизм отношений делает их счастливыми. Находясь на пике разрушения своей жизни, героиня уверенно заявляет, что источник ее счастья заключен исключительно в любви к мужу: «В моей жизни был только один человек, который сделал меня счастливой. Это мой муж Джордж. Он хорошо ко мне относится, а я осыпаю его бранью. Он хочет сделать меня счастливой, а я противлюсь этому. Нет, я очень хочу стать счастливой». (There's only been one man in my life who's ever made me happy. My husband. George. Who is good to me. Whom I revile. Who can make me happy and I do not wish to be happy. Yes, I do wish to be happy.) [9].

К числу факторов, образующих ассоциативный контекст концепта в данной пьесе, можно отнести безжалостное уничтожение друг друга, споры до хрипоты, попытки утвердить свое главенство, полное изнеможение в борьбе за самоутверждение, духовное обнажение перед друг другом. Баланс благополучия сместился в сторону его разрушения, что-то не дает героям жить по единожды установленным канонам, двигаться в направлении созидания и успеха. Но именно несчастье становится «проводником» в мир их счастья. Этим выражение концепта существенно отличается от русской лингвокультуры, в которой укоренилась иная формула счастья, признающая приоритет таких факторов, как удовлетворенность человека полнотой своего бытия, осуществление своего предназначения, сопутствующая ему удача.

Поиски возможностей консолидации личности на основе экзистенциальной логики жизни получают дальнейшее развитие в пьесе Э. Олби «Три Высокие Женщины» (Three Tall Women, 1994). Театральные критики оценили ее как шедевр, глубокий портрет жизненного цикла и незабываемую встречу со смертью. Подчеркивая заслуги Э. Олби в создании образов реальных людей «из плоти и крови», газета «Чикаго Трибьюн» отметила жизнеутверждающее начало его творчества: «Есть одна великая истина, выраженная в «Трех высоких женщинах», которая завораживает. Это ... признание нашего разумного «я»» [10]. В предисловии Э. Олби отмечал, что поводом к написанию пьесы послужили воспоминания о своей приемной матери, жизнь которой прошла на его глазах, и с которой у него были весьма сложные отношения. Он вспоминал, что работал над пьесой с большим 
интересом, околдованный ужасом и печалью того материала, который он пробудил к существованию. ("I recall being very interested in what I was doing - fascinated by the horror and sadness I was (re) creating.") [11].

Пьеса «Три Высокие Женщины» состоит из двух частей, в каждой из которых действуют три героини. В первой части участвуют главная героиня, обозначенная буквой $\mathrm{A}$, ее сиделка и помощница ее адвоката (B, C); во второй части все три предстают тремя возрастами одной героини. Женщина «С», пишет Олби, выглядит так, как выглядела бы «В» в 26 лет, «В» выглядит так, как «А» выглядела бы в 52 года, «А» продолжает пребывать в своей роли 92-летней старухи. Автор легко перемещается по трем возрастам: три женщины - это по сути одна, только изображенная в трех разных возрастах, они едины в трех лицах. У них общая биография и общая судьба. Отдельные компоненты «формулы счастья» (радость, покой, удовлетворение, благополучие) гипостазируются в ментальных структурах трех героинь, через которые раскрывается сущность авторской модели. Представления о счастье демонстрируют гибкость и подвижность, и в то же время суммарно конституируют человеческий опыт. Ощущение счастья у героини «С» (26 лет) ассоциируется с детскими воспоминаниями о матери, сшившей ей красивое белое платье, о сестре, ревностно относившейся к ее обновкам и частенько пребывавшей в дурном настроении. Ее вектор счастья устремлен в будущее, размышления о прекрасном будущем наполняют ее существо. «Ведь я еще не испытала самые счастливые моменты, не так ли? - задается вопросом героиня, - некоторые моменты счастья конечно состоялись, возможно потом их можно будет причислить к самым счастливым». ("What about ... the happiest moments? I haven't had them yet, have I? I had some, of course, some of what probably will be the happiest") [11, p. 107]. Но и в этом прекрасном возрасте молодости и любви ощущение счастья коррелируется с упоминаниями об утратах, бедах, неминуемом зле. В свои 26 лет она уверена, что те самые лучшие, наисчастливейшие времена, которые еще не наступили, смогут смягчить любые несчастья, беды, потери ("I know my best times haven't happened yet. They are to come. And... whatever evil comes, whatever loss and taking away comes, won't it all be balanced out?") [11, p. 107]. Таким образом, счастье будущего не безоблачно, в нем изначально присутствуют мотивы разочарования и пессимизма, служащие контрастным фоном объектно-ориентированной модели.

В героине «В» (52 года) значительная часть иллюзий погашена, возобладала грубая и часто неприглядная реальность, еще теплятся определенные надежды, но вероятность того, что они осуществятся, ничтожна мала. Вместе с тем, по мнению героини «В», этот возраст и есть наисчастливейший, так как половина задач взрослой жизни реализована, после тупости и дурости мо- лодого возраста приходит мудрость, а главное - ты уже находишься на пике, на вершине жизни, и именно это положение и является наисчастливейшим, поскольку человек, говоря словами Олби, «обретает способность видеть все вокруг себя на все 360 градусов». ("It has to be the happiest time. I mean, it's the only time you get a threehundred-and-sixty-degree view - see in all directions") [11, p. 109]. Однако и здесь автор не позволяет нам с замиранием сердца восхищаться исключительной красотой разворачивающейся перед нашими глазами панорамы. Нам открываются и картины упадка, старения, странностей и причуд, но главным мерилом счастья этого возраста выступает тот факт, что многие испытания остались позади, они преодолены и пройдены, не относятся более к категории ожидаемых. ("It opens up whole vistas - of decline, of obsolescence, peculiarity... What I like most about being where I am is that there's a lot I don't have to go through anymore...") [11, p. 109].

Итак, комические диалоги в первой части пьесы постепенно превращаются в исповедальные монологи во второй. А что же героиня, обозначенная буквой «А» (92 года)? Это очень пожилая женщина, худая, аристократичная, гордая, насколько позволяет разрушительное воздействие возраста. Добавим также - капризная, обидчивая, эгоцентричная, требовательная. Она с трудом может сидеть, и практически не передвигается без посторонней помощи; дожив до 90 лет, она испытывает чисто физические страдания от того, что ее истончившиеся кости ломаются и не срастаются; реальная связь с миром утеряна - провалы в памяти, прогрессирующая старческая деменция налицо: человек все более отдаляется от реальности и погружается в мир воспоминаний. Тем не менее, героиня не утратила интереса к главным проблемам бытия: она легко вступает в дискуссию о счастье, судьбе и смысле жизни, не переставая удивлять нас своими размышлениями. «Самый счастливый момент жизни? Я думаю, утверждает героиня, прийти к концу всего этого, когда все бури стихают и можно сконцентрироваться на самой большой проблеме - завершении всех проблем вообще. ... всякая чушь, по типу «все впереди» уже не заботит тебя, до такой степени, что ты можешь думать о себе в третьем лице, не будучи сумасшедшей». ("The happiest moment? Coming to the end of it, I think, when all the waves cause the greatest woes to subside... time to concentrate on the greatest woe of all - the end of it. None of that "further shore" nonsense, but to the point where you can think about yourself in the third person without being crazy...") [11, p. 109]. Результат жизни: это третье лицо $\mathrm{OH}, \mathrm{OHA} \mathrm{-} \mathrm{некая} \mathrm{нетленная} \mathrm{субстанция,} \mathrm{которая} \mathrm{образо-}$ валась на излете человеческой души.

Пьеса завершается пронзительным утверждением счастья на пороге неминуемой смерти: «Вот когда наступает самый счастливый момент. Когда все завершается. Когда мы останавливаемся. Когда мы можем 
остановиться». ("That's the happiest moment... When it's all done. When we stop. When we can stop.") [11, p. 110]. B результате, счастье узнавания мира трансформируется в счастье опыта, которое теряет свой смысл, преобразуясь в мудрость преодоления и растворяясь в вечном покое. Концептосфера Э. Олби отражает прежде всего душевное состояние человека, которое находится в зависимости от многочисленных субъективных переживаний, от возрастных и социальных различий. Путь человека к счастью неизбежно лежит через трудности и испытания. В его экзистенциальной модели сущностной характеристикой служит контраст, сложное балансирование между счастьем и несчастьем, горем и радостью, а конечный исход переживания - иррационален и парадоксален.

Таким образом, анализ глубоких философско-культурных смыслов, заложенных в авторских лингвоконцептах счастья прошлого века, показывает, что счастье это многомерное образование, включающее в себя коннотативные, образные, оценочные, ассоциативные характеристики. Представления о счастье отражают многогранность личности, ее социальную и возрастную рефлексию, помноженную на конкретный исторический контекст. Язык персонажей, благодаря его кумулятивной функции, сохраняет философско-этимологические представления авторов, обеспечивая преемственность основных концепций на уровне диалога поколений, и их передачу из прошлого в настоящее. В результате, если с позиций прошлого века свойственное А. Камю и Э. Олби восприятие действительности с акцентом на ее абсурд и иррациональность могло рассматриваться как национально специфическое, в XXІом веке оно представляется вполне универсальным. Мировоззренческие паттерны этих авторов прошли испытание временем и оказались востребованными в наши дни, когда общество всерьез задумалось о сохранении человеколюбия. В глобальном социальном пространстве гуманистические модели счастья обретают новое звучание на путях продвижения к постковидной нормальности.

ЛИТЕРАТУРА

1. Международный день счастья. [Электронный ресурс]. URL: https://ru.wikipedia.org/wiki / (Дата обращения 17.01.2021)

2. Гйдаровский форум 2021. Дискуссия о счастье. [Электронный ресурс]. URL: https://gaidarforum.ru/ru/program/937/ ( Дата 0бращения 22.01.2021)

3. Лихачев Д.С. Концептосфера русского языка. Известия ОРЯ, Серия литературы и языка. - 1993. - Т. 52, № 1. С. 3-9.

4. Камю Альбер. Википедия. [Электронный ресурc]. URL: https://ru.wikipedia.org/wiki/ (Дата обращения 28.01.2021)

5. Carlos Franco-Paredes. Albert Camus'The Plague Revisited for Covid-2019. [Электронный ресурс]. URL: https://academic.oup.com/cid/ article/71/15/898/5821271 (Дата обращения 23.01.2021)

6. Театр абсурда. [Электронный ресурc]. URL: https://ru.wikipedia.org/wiki/ (Дата обращения 25.01.2021)

7. Руднев Павел. Что такое «театр абсурда»? [Электронный ресурс]. URL:https://thequestion.ru/questions/122970/chto_takoe_teatr_absurda_chto_tam_ takogo_0622dc6а (Дата обращения 26.01.2021)

8. Степанов Ю.С. Концепт // «Константы. Словарь русской культуры». Опыт исследования. М., 1997. С. 42-84.

9. Edward Albee. Who's afraid of Virginia Woolf? [Электронный ресурc]. URL: http://www.script-0-rama.com/movie_scripts/w/whos-afraid-of-virginia-woolfscript.html (Дата обращения 26.01.2021)

10. Chris Jones. Why playwright Edward Albee mattered. CHICAGO TRIBUNE. SEP 17, 2016. [Электронный ресурc]. URL: https://www.chicagotribune.com/ entertainment/theater/ct-edward-albee-appreciation-ent-0918-20160917-column.html (Дата обращения 1.02.2021)

11. Edward Albee. Three Tall Women. First Plume Printing. USA. 1995. - $112 \mathrm{p}$.

(c) Макарова Татьяна Генриховна (fortunatat@mail.ru).

Журнал «Современная наука: актуальные проблемы теории и практики» 